\title{
Research and application Based on hammer modal testing of slender body in two-point excitation vibration
}

\author{
Chen Zhao1, Pengbing Chen1, Chao Ma1 \\ 1China Aero-Polytechnology Establishment, Beijing 100028, China \\ email: zhaochen913@163.com
}

\begin{abstract}
The vibration testing program including excitation location, control location and hanging location has important influence in the slender body two-point excitation vibration test. The modal test results will be referenced when selecting the testing program before the two-point excitation vibration test. Based on the principle of testing program and the modal test theory, a calculation formula will be established when select the testing program using the modal test results. Through the calculation results, we can know that the two testing programs can be intuitively comparison.
\end{abstract}

Keywords: Slender, Modal testing, Two-point excitation, Control location

\section{Introduction}

At this stage, the multiple-input multiple-output vibration test of slender body is commonly used two vibration table, and the excitation test control is used two control points too. In the vibration test of two-point excitation, the complex characteristics of dynamics of slender body will have great impact on the control results [1] [2].

In the test process, when the incentive points (or the location of fixture) is improper, it will cause local response become bigger, eventually, it will make test control overstep error even cannot control, seriously it will cause damage to the test sample structure; when the control point is improper, it will cause over test or test deficiency, but when the control point is proper, for example, the control point is selected in the wave crest of the shake, so the control effect will get more better in some control way. Thus, when we want to get proper control way in the slender body two-point excitation vibration test, it is important to take some modal test for test body. Although it can get the information of the control overstep error easily by the modal test, it is not enough to the test body, in that there are many problems that is the modal test results application in the vibration test of two-point excitation in the test [3]. These problems include a little information of modal test results (wave crest) is used in the test scheme, in addition to including the selection of the test scheme、 unable to quantify and so on. Therefore, in this article, we will take the modal data of the slender body by 
the hammer modal testing, and will quantitative study to the two-point excitation vibration test method based on these modal data.

\section{The principle of hammer modal testing}

Structural modal information consists of a range of frequencies, modal damping and modal form. The basic structure modal information can be measured by modal testing. Currently, the common incentive method is the platform of incentive and hammer incentive. The hammer excitation belongs to transient excitation (or pulse); the principle of transient excitation unit impulse function is used on the incentive structure objects to be measured. The pulse duration close to zero and the frequency range is infinite and continuous. In the excitation pulse broadband signal, the natural frequency of test subjects could be around. The basic procedure of hammer is to use a hammer to excite on the hammer point and measure the incentive response in signal collecting spot, the equipment of signal acquisition and analysis acquisition incentive and respond signal, the transfer function of the response can be obtain through incentives signals and response signal solution in computer, even it can get the modal information of structure. As for modal testing, response signal is the acceleration signal in the collecting spot [4] [5].

The advantages of this Hammering method are:

1 There is no need special signal source;

2 There is not produce additional mass and additional stiffness and other side effects on the specimen;

3 The selection of incentive point is not limited by the hammer itself structure;

4 It can be conveniently carried out experiments in the production site;

5 The speed of obtained testing data is fast and high efficiency.

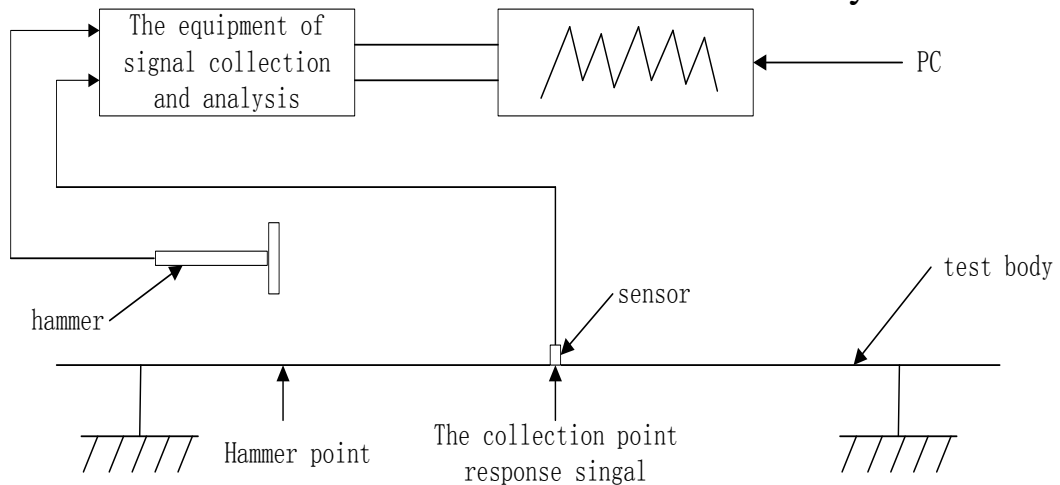

Fig. 1 the Process of hammer method

There are two kinds of testing methods of the hammer test: the first method is to use the acceleration sensor which acquisition point measuring hammer in a fixed position, the hammer is applied in each unit one by one, the condition is called "mobile hammer" which generally only need a sensor to measure the response acceleration. The second method is that hammer is applied in a fixed point, and measuring response of all other points, this is termed a "fixed 
hammer" which need sensors as much as possible cover the setting model unit fixed-point hammering.

\section{Modal test data analysis}

The equations of dynamics of multi-degree of freedom system is[6] [7]:

$$
\left([\mathrm{K}]+j \omega[C]-\omega^{2}[M]\right)\{X(\omega)\}=\{F(\omega)\}
$$

(1)

where $[\mathrm{M}],[\mathrm{C}],[\mathrm{K}]$ are the mass, damping, and stiffness matrices respectively.

$\{\mathrm{X}\},\{\mathrm{F}\}$ are the response to vector and force vector respectively.

$$
\{X\}=[\Phi]\{q\}
$$

where $[\Phi]$ is Modal matrix, $\{q\}$ is modal Coordinates, then:

$$
\left([\mathrm{K}]+j \omega[C]-\omega^{2}[M]\right)[\Phi]\{q\}=\{F\}
$$

According the orthogonality relations of the modal matrix, the mass, stiffness and damping matrix will be diagonaled and the decoupled equation will be express as the $\mathrm{n}$ degrees of freedom system of equations with independent of each other in modal coordinates. After decoupling, the equation as follows:

$$
\left(k_{i}-\omega^{2} m_{i}+j \omega c_{i}\right) q_{i}=\sum_{j=1}^{N} \phi_{i j} F_{j} \quad(j=1,2, \cdots, n)
$$

(4)

Transfer function of modal parameter is represented as:

$$
H(\omega)=\sum_{r=1}^{n} \frac{\left\{\phi_{i}\right\}\left\{\phi_{i}\right\}^{T}}{m_{r}\left(\omega_{r}^{2}-\omega^{2}\right)+j 2 \xi_{r} \omega \omega_{r}}
$$

$$
\text { where } \omega_{r}^{2}=\frac{k_{r}}{m_{r}} \text { is the R-order Modal frequency, } \xi_{r}=\frac{c_{r}}{2 m_{r} \omega_{r}} \text { is the }
$$

R-order Modal damping ratio.

Supposing the order of $r$ mode natural frequency is used to excite, the largest contribution portion be only considered in the equation (5), then equation (5) can be expressed as:

$$
H_{i j}\left(\omega_{r}\right) \approx \frac{\phi_{i, r} \phi_{k, r}}{2 j \xi_{r} \omega_{r}^{2}}
$$

We can see that the largest contribution part is proportional to the displacement vector, therefore, the displacement amplitude of modal as follows:

$$
\text { displacement amplitude } \propto \frac{\phi_{i, r} \phi_{k, r}}{\omega_{r}^{2}}
$$


(7)

According to the displacement, acceleration of expression:

$$
\begin{aligned}
& x(t)=X(t)^{i \omega_{r} t} \\
& \ddot{x}(t)=-\omega^{2} X(t)^{i \omega_{r} t}
\end{aligned}
$$

We can get the modal coordinates of acceleration, the amplitude of relationship:

Acceleration amplitude

Acceleration amplitude $\propto \phi_{i, r} \phi_{k, r}$

\section{Study on test method}

The two-point excitation test of slender body is a typical multiple-input and multiple-output test. If there are drive signal drive system of $\mathrm{m}$ and the response signal of $\mathrm{n}$ in multiple-input and multiple-output vibration test system, then the relationship between driving signals and control signals can be described as:

$$
\left\{C_{m}(f)\right\}=\left[H_{m \times n}(f)\right]\left\{D_{m}(f)\right\}
$$

\section{(11)}

When $\mathrm{m}=\mathrm{n}$, that the incentive points are same as the number of control points of the vibration tests. $[H(f)]$ is square, and it has inverse, the feature are the convenient solution and control easily in test, so carry out a pilot scheme at two exciting test of control points usually equal to the excitation points.

When you select a pilot programme, we should need to reference specimens of slender body mode information, it includes: natural frequency; vibration wave of modal that is the max value of each order modal shape; mode lines, the place of each mode of vibration is equals to zero. Different locations have great impact for tests. The exciting location selection is a primary factor in the success of two exciting test, improper selection might make some modal frequency response is very weak or not keep it out. Exciting position should ensure that the incentive structure of the excitation source energy modes and structures have great response at different frequencies. When choosing a hanging position at minimum displacement response of structures location should be chosen to reduce interference that is selected in the mode line.

\subsection{Exciting location select the method of calculation}

When the exciting location is placed in a certain order mode lines on or near the location in the vibration test, there is only a very small amount of energy delivered to the modes, in order to the modal frequency response is very small, so the most suitable vibration position should be ensure that the bigger on different frequency response of the structure.

To avoid vibration mode lines, and incentive structures in response to the largest, the exciting layout should be away from the structural position of the 
section the first mode shape, such as equation (12), it is take the product of each order mode shape on point value results for structure as the optimal excitation parameter value for each point.

$$
O P(\mathrm{i})=\prod_{r=1}^{m}\left|\varphi_{i, r}\right|
$$

Where $\varphi_{i, r}$ is r-order mode of vibration in point I of the structure, $\mathrm{R}$ as the order of modal, $\mathrm{m}$ is the total number of modal order for structural.

The higher value of OP means that the point is away from the liner position for each mode of vibration of structural, and this point can be considered as exciting. The OP point of close to zero means that the point is near to the liner positions of the order mode shape, so the vibration point should be avoided as much as possible to these positions.

The maximum number OP values obtained through calculation will not necessarily select as an exciting location in test, it also need know the actual usage of slender body to tradeoffs. The location choice will be the best fit for exciting locations. In addition, if exciting locations of the two-point excitation vibration test have been identified, we can study the response situation of the exciting locations on the test piece through calculating all the OP value of the reference points, and adjust the control parameters according the exciting locations.

\subsection{Calculation method of the control position selection}

The principle of control position selection was consistent with the exciting choice, and therefore the parameter calculation of the control position also can be show through equation 9. It is similar with exciting location, the bigger OP value, the better control position. There will get the first 6 order modal data to be used calculated in practical. Through calculating the value of OP, the larger value can be used as the alternative control point, we can choose the proper point according the test situation.

\subsection{A hanging position selects the method of calculation}

It should be simulated specimens of the "free-free" condition in the slender body two-excited vibration test. Generally speaking, it will be achieved by using a soft spring or rubber rope suspension. But we must pay attention to make the structure of the interference to a minimum when we select soft rubber rope hanging position on the specimen. Therefore we should choose the minimum displacement response of structures which will minimize disruption of the experiment. Mathematical expression of the displacements response parameter value in the structure inspired as shown.

$$
O F(\mathrm{i})=\sum_{r=1}^{m} \frac{\left|\varphi_{i, r}\right|}{\omega_{r}^{2}}
$$

OF is the parameter values of displacement response of the structural model at 
that point. The smaller value, the smaller average displacement, and then we can know that these points are closer to the structure of each order mode lines, and these points are adopted as the suspension points. So it can be more closely imitate the structure of free-free boundary conditions.

The equation (13) decrease the impact of the higher orders modal data with some extent, because the main factor for the structural displacement effects is the previous order modal of the structure. If the previous modal frequencies is greater than $200 \mathrm{~Hz}$, and the calculated results were very close, then this means that each point as a hanging position is no different.

\section{Experiments and results analysis}

In this paper, we will use the LMS Test.lab software to a specimen"modal experiment of free-free" of a slender body. Through the modal test, we can get the modal information in Figure 2 which has two suspensions as shown in table 2. The hanging position OF values see table 3 .

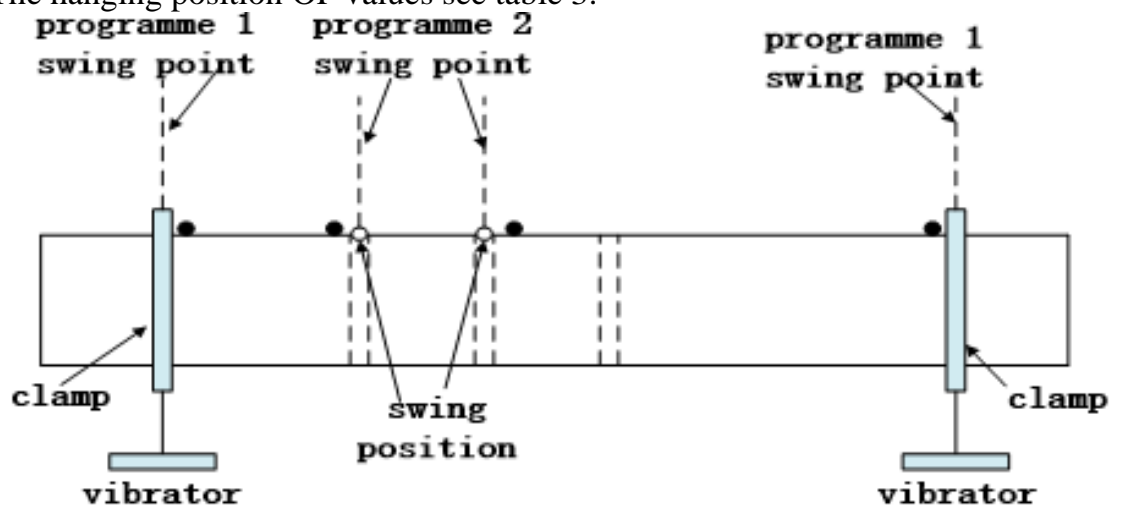

Fig. 2 the Process of hammer method

From Table 1 and Table2, we can see that the average calculates value of programme $1(8.61 \mathrm{E}-10)$ is less than the programme $2(1.48 \mathrm{E}-9)$, so, the conclusion is the programme 1 is better than programme 2 . In order to validate the calculation results, we tested two scenarios separately, results as shown in Figure 3 and Figure 4. Figure 3 testing is the use of programme 1 of the control chart; Figure 4 is tested using scenario 2 control charts. From Figure 3 and Figure 4, we can clearly see that the control effective of programme 1 is more effective than programme 2.

Table 1 the modal information of blender body in pre five-order

\begin{tabular}{|c|c|c|c|c|}
\hline $\begin{array}{c}\text { Frequ } \\
\text { ency/ } \\
\mathrm{Hz}\end{array}$ & $\begin{array}{c}\text { The first } \\
\text { point in } \\
\text { programme } \\
1\end{array}$ & $\begin{array}{c}\text { The second } \\
\text { point in } \\
\text { programme 1 }\end{array}$ & $\begin{array}{c}\text { he first } \\
\text { point in } \\
\text { programme } \\
2\end{array}$ & $\begin{array}{c}\text { The second } \\
\text { point in } \\
\text { programme 2 }\end{array}$ \\
\hline 52.34 & $-5.12 \mathrm{E}-07$ & $-2.39 \mathrm{E}-06$ & $1.91 \mathrm{E}-06$ & $2.99 \mathrm{E}-06$ \\
\hline 76.3 & $7.81 \mathrm{E}-07$ & $3.10 \mathrm{E}-07$ & $-1.35 \mathrm{E}-06$ & $-8.66 \mathrm{E}-07$ \\
\hline
\end{tabular}




\begin{tabular}{|c|c|c|c|c|}
\hline 92 & $2.20 \mathrm{E}-07$ & $1.25 \mathrm{E}-06$ & $1.37 \mathrm{E}-06$ & $-2.90 \mathrm{E}-06$ \\
\hline 132 & $4.33 \mathrm{E}-06$ & $5.47 \mathrm{E}-07$ & $2.61 \mathrm{E}-06$ & $8.19 \mathrm{E}-08$ \\
\hline 176 & $-1.50 \mathrm{E}-07$ & $-4.66 \mathrm{E}-07$ & $-1.65 \mathrm{E}-06$ & $-9.44 \mathrm{E}-07$ \\
\hline
\end{tabular}

Table 2 the compared results of two test method

\begin{tabular}{|c|c|c|c|c|}
\hline method & $\begin{array}{c}\text { The first } \\
\text { point in } \\
\text { programme } \\
1\end{array}$ & $\begin{array}{c}\text { The second } \\
\text { point in } \\
\text { programme } \\
1\end{array}$ & $\begin{array}{c}\text { The first } \\
\text { point in } \\
\text { programme } \\
2\end{array}$ & $\begin{array}{c}\text { The second } \\
\text { point in } \\
\text { programme } \\
2\end{array}$ \\
\hline $\begin{array}{c}\text { OF } \\
\text { value }\end{array}$ & $6.01 \mathrm{E}-10$ & $1.12 \mathrm{E}-9$ & $1.30 \mathrm{E}-9$ & $1.66 \mathrm{E}-9$ \\
\hline
\end{tabular}

Therefore, in this paper, through analyzing the modal test results, we initially establish a calculation method of pilot programme, which provide a quantitative method for the slender body in two-point excitation vibration test. This method also provide a feasible for the future in the process of testing, and the test personnel will use model information in different scenarios to choose more appropriate test protocols which can laid a certain Foundation.

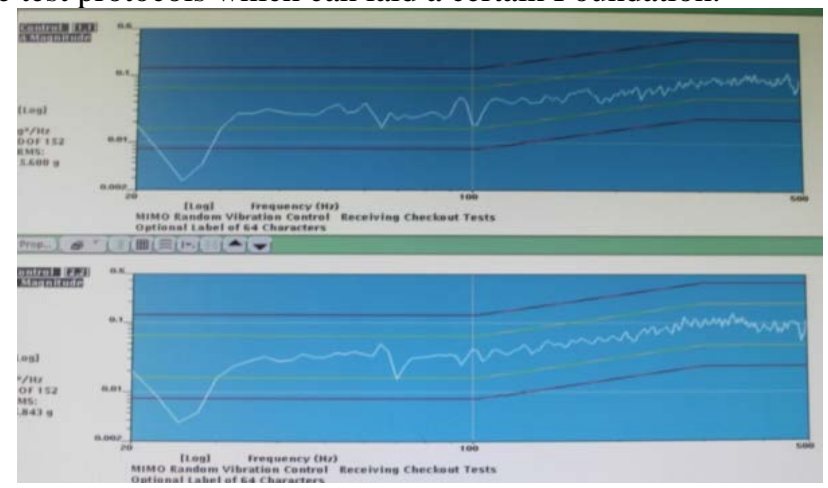

Fig3. the control line of programme 1

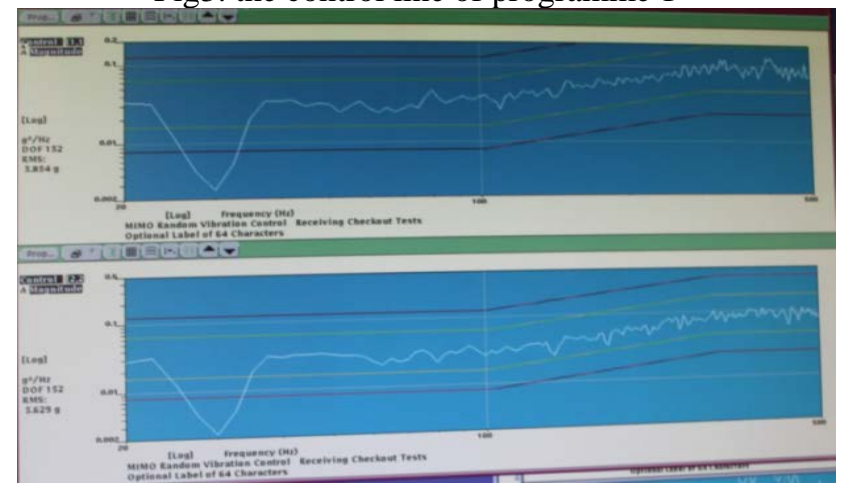

Fig4. the control line of programme 2

\section{References}


[1] Hamma G. STI multiple vibration exciter control replicates the real world in your laboratory [J]. STI Journal, 1989, 1(2): 1-4.

[2] Heylen W, Sas P. Modal analysis theory and testing[M]. Katholieke Universteit Leuven, Department Werktuigkunde, 2006.

[3] Imamovic N. Validation of large structural dynamics models using modal test data[J]. Imperial College. London, 1998: 46 54.

[4] Hakim S, Fuchs M. Optimal actuator placement with minimum worst case distortion criterion[A].Proceedings of AIAA 36th Structures, Structural Dynamics, and Materials Conference and Adaptive Structures Forum[C]. 1995: 56.

[5] Huaigeng Zhao, Guangming Tian, Jigeng Zhong. Analysis of two vibration test structure modal on the control effect[J]. Equipment Environmental Engineering, 2012,9(6): 51-53.

[6] Ward Helen, etc. The theory of modal analysis and test [M]. Beijing Institute of Technology press, 2001.

[7] Debao Li, Qiuhai Lu. The experimental modal analysis and its application [M]. Science Press

, 2001. 